bandied about from one specialist to another until they lose faith in medical art.

Another point that will explain some of the causes of sterility is the abnormality of the internal secretions. I hesitate to make that statement because it throws us into an immense field that is very dimly lighted by positive knowledge, but I do know cases that have been unsuccessfully treated elsewhere and have been successfully treated by the glands of internal secretion-thyroid and other extracts. In some instances administration of these preparations has been followed by impregnation, especially that type of firm fat olsesity, in which the women are round and plump and the fat is hard, almost like firm flesh, and the periods are inclined to be irregular and small in amount. Thiose cases have responded to combined treatment occasionally.

The use of alkaline douches just before intercourse deserves mention. The husband, as a cause of the sterility, must he always emphasized, and I have found that excessive smoking of tohacco is occasionally a cause of sterility. and that alcohol, even when the spermatozoa are alive and motile, indirectly prevents them from successfully fertilizing an ovum; that workers in arsenic, antimony, and other chemicals, in spite of live spermatozoa are sometimes sterile. Then I have had men who have had syphilis and are sterile, even though the examination of the semen showed motile spermatozoa. The sperm injected into the woman has both a local and a general effect. It has been demonstrated that the spcrmatozoa not used for fertilization enter the cells of the genital tract and are absorbed into the cell. This is a line of light on the immunal theory. Isn't it possible that a woman can be immunized; her serum so protected against the advent of the spermatozoa that it dissolves them when they come? Perhaps this explains-when the husband or wife has been sent away for six or eight months-successful fertilization. The law of incompatibles thus bids fair to be explained.

Dr. H. O. PAntzer. Indianapolis: His, the anatomist, said that the complexity of the genitalia in the human female is such as to make it, to him, a surprise that woman ever conceives. Regarding the nervous excitability referred to, I have this observation to mention, that women who have delayed menstruation frequently give evidence of a presenile sclerosis of the orum. These cases are often associated with chronic intestinal auto-intoxication. This interrelation of toxemia and ovarian sclerosis is not surprising when we recall that toxemia strikes essentially at all glandular organs, and in all is followed by withering and sclerotic changes. It is surprising how many cases of spanomenorrhea or amenorrhea are helped by looking after systemic elimination. All will remember the reliance the older practitioners and gynecologists placed on elimination, as evidenced by the free laxative remedies invariably contained in their prescriptions.

Dr. Edward Reynolds, Boston: Some of the points about which Dr. DeLee spoke were omitted in my reading, but were in the paper.

I do not think the bicarbonate of soda routine for the acid vagina is a good thing. The acid nature of the vaginal secretions is, in all probability, merely the most superficial indication of the chemical changes which destroy the spermatozoa. The failure of such treatment in the vast majority of cases, is because we only neutralize the acidity and not the other chemical alterations. I am unable to speak as yet of various studies which I have made, and have had made, and am making on the chemical and microscopic character of the secretions. So far as I know, the chemical and microscopic examination of the mixed secretion of the male and the female, as obtained from the female genitals; is, as yet, an entirely virgin field. There have been a number of men who have observed the spermatozoa and their action in those fluids, but the essential point which we cannot yet speak of is the microscopic and chemical examination of the mixed secretions; the establishing of a normal standard and the detection of abnormality. I have learned to recognize certain arrangements of pus cells, and have seen the spermatozoa swimming freely, come into one of those pus cells, tanglc his poor little tail in it, stop his progress, thrash, thrash, thrash. and lie dead. Jou have to reduce that apparently normal cervical secretion. There are dozens of such things that we know nothing of. The question of immunity is a very curious and interesting one but from a practical standpoint on both the question of abnormal chemistry and immunity we must be careful how we determine our action in such cases by subjects that are so little worked out that our knowledge is hardly a gleam in the obscurity of our ignorance.

\section{RELATIVE FREQUENCY OF ECTOPIC GESTATION *}

ALFRED BAKER SPALDING, A.B., M.D.

Professor of Obstetrics and Gynecology, Leland Stanford Junior University, School of Medicine

\section{SAN FRANCISCO}

Why an impregnated ovum should implant and develop outside the uterus so relatively frequently in the human species and fail to do so in lower animais is a question the answer to which has been sought through investigation by clinicians and laboratory workers for a great many years. Clinicians agree that ectopic gestation is a frequent abnormality of early pregnancy but vary in their estimates of frequency depending on whether their clinical experience has been gained as a necropsy surgeon, a gynecologist, an obstetrician or a general practitioner. The large number of case reports indicate the frequency with which this condition is met by surgeons, but is too irrelevant to be of aid in discussing the subject statistically. In this paper, a statistical study of a definite number of patients will be made in order to estimate the relative frequency of ectopic gestation to disease in generai. to women's disease, to pregnancy and to abortion. The small material presented makes the importance of the subject the sole excuse for presuming to answer these difficult questions.

The necropsy surgeon reports that he frequently meets ectopic gestation because sudden death associated with such a condition requires his services to satisfy the demands of the law. The gynecologist considers ectopic pregnancy a frequent condition because he does not take into account the many ordinary conditions which the man in general practice has treated before referring to him the patient with ectopic pregnancy. The obstetrician considers ectopic gestation a relatively rare condition because, through lack of understanding, the laity are prone to come to him only after the first three dangerous months of pregnancy are passed. It is an odd experience that a general practitioner may encounter several ectopic pregnancies quite close together and then practice for some time without meeting a case.

Formad, ${ }^{1}$ who was a coroner's physician in Philadelphia, in 3,500 routine necropsies, found thirty-five deaths from ectopic pregnancy. Michel ${ }^{2}$ has reported twenty-six cases of ectopic gestation in 6,000 gynecologic conditions, while $\mathrm{Hartz}^{3}$ reports 3.4 per cent. of ectopic pregnancy in 1,700 specimens examined in the gynecologic laboratory at Jefferson and St. Joseph's hospitals in Philadelphia. Hennig stated some years

* Read before the Section on Obstetrics, Gynecology and Abdominal Surgery at the Sixty-Sixth Annual Session of the American Medical Association, San Francisco, June, 1915.

1. From an unpublished communication by Ellice McDonald.

2. Michel: Fortsehr. d. Med., 1914, No. 23, p. 637.

3. Hartz: Am. Jour. Obst., 1915, 1xxi, 601.

4. Hennig: Die Krankheiter der Erleiter und die Tubenschwanc.... scliaft, Stuttgart, 1876 . 
ago that the directors of even large obstetric institutions might never encounter a case.

Although ectopic gestation is discussed in textbooks on obstetrics, no modern obstetrician has, to my know!edge, ventured an opinion of its frequency based on his personal experience. My own experience has been that for ten years, while limiting my practice to obstetrics, I did not treat a case of ectopic pregnancy in private or clinic work, but during the last three years while combining gynecology with obstetrics, I hate operated on thirteen clinic patients and on seven private patients for this condition. The clinic cases form the basis for this paper as they were encountered at fairly regular intervals in a comparatively large number of patients.

From July 1, 1912, to May 1, 1915 (the time of writing), 36,668 patients have registered in the outpatient clinics of the Leland Stanford University, School of Medicine. Of this number, 2,955 have been treated in the women's clinic. In the clinic, fairly
The remaining group of 1,176 patients who did not enter the hospital includes undoubtedly some eases of pregnancy, but is composed largely of nonpregnant patients such as come to all clinics for treatment of minor gynecologic ailments, as well as patients past the childbearing period, and a few children. The statistical work with this group is not as accurate as with the hospital group and the proportion of pregnant to nonpregnant patients can be estimated only roughly. Stiil it is important to include with the known pregnancies a fair number of these doubtful cases. For ten years, I have recorded annually the percentage of pregnant patients that have failed to return to the San Francisco maternity clinic for confinement, and have found that, on the average, 25 per cent. of the applicants do so fail to return. Applying this experience to the present clinical material, 393 of the 1,176 doubtful cases, or 30 per cent. of the number of confinements, have been grouped with the known pregnancies, making a total of 1,704 pregnancies, and 783 have been grouped with

CLINICAL SUMHARI OF ETIOLOGIO CONDITIONS IN JCTOPIC GJSTATION

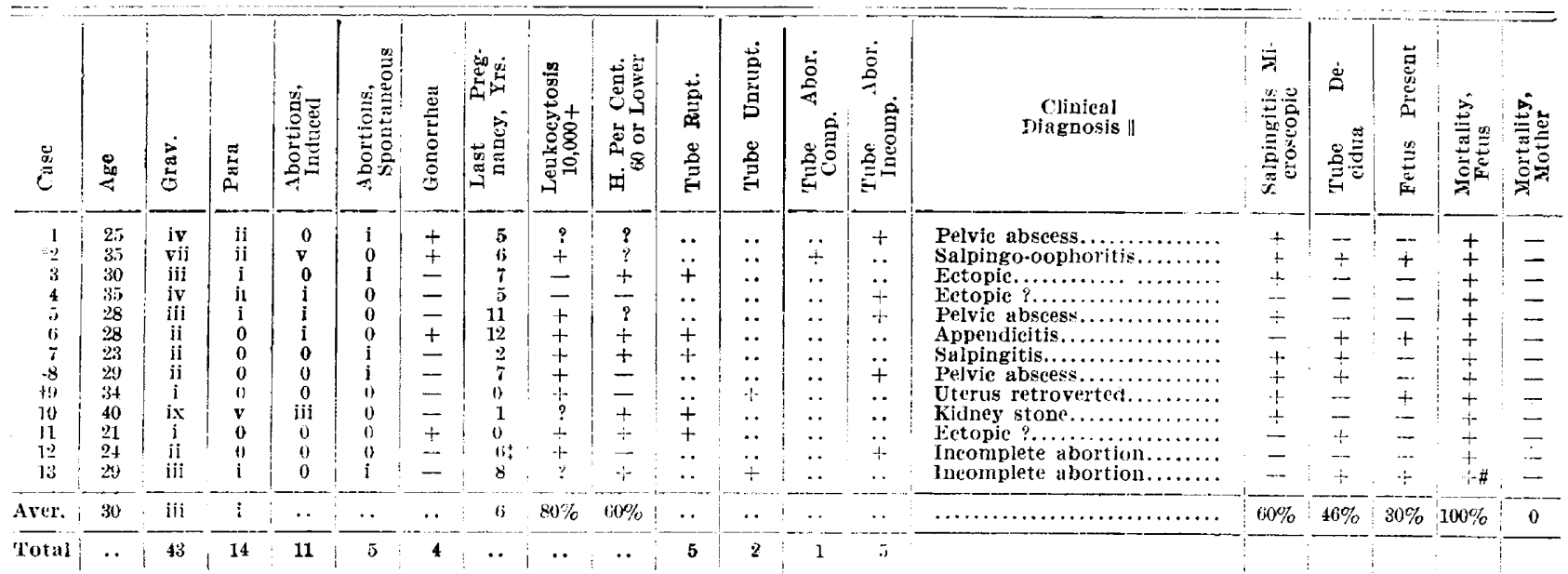

* At operation there was found a leather-like fetus $3 \mathrm{~cm}$. long compressed between a pus tube and the fibrous uterus. The patient surviverl a tube abortion, which undoubtedly occurred six years ago, associated with an attempted criminai abortion.

In the laboratory there was found a hematosalpinx containing cartilage cells which, with the history, gave evidenee that the patient survived an ectopie pregnancy four years ago, mistaking the conditions for a spontaneous abortion.

\$ Eetopic pregnaney. Left tube and ovary remored. I| On hospital entrance slip.

\# Fetus alive at time of operation.

extensive histories of the patients were taken and a careful pelvic examination made, as well as considerable routine laboratory work started. A presumptive clinical diagnosis was entered on the history as soon as conditions justified such procedure. These facts are mentioned because often the diagnosis of early pregnancy is impossible, and because some patients, so soon as that diagnosis is made, fail to report to the clinic. Many cases of pregnancy abort or are aborted after leaving the clinic, and possibly some cases of ectopic gestation are overlooked. Taking these facts into consideration, it is interesting to note that of the 2,955 patients registered in the women's clinic, 554 were operated on for various gynecologic conditions. Of these, 353 were curetted and the curettings, together with the associated pathology, were studied in the laboratory for obstetrics and gynecology.

From these specimens there have been made seventythree laboratory diagnoses of incomplete abortion and thriteen diagnoses of ectopic pregnancy, 1,225 of the 2,955 patients were confined by the clinic at or near term, which makes a total of 1,311 known pregnancies and 468 patients operated on who were known not to le pregnant. the operated patients, making a total of 1,251 nompregnant patients.

From these figures, it will be seen that we have met cotopic gestation thirteen times in 36,668 patients or once in 2,820 cases of illness such as a general practitioner would encounter in a practice covering the diseases of men, women and children. Thirteen rases of (ctopic gestation among 2,955 women with pelvic symptoms, or once in 227 cases stich as come to the specialist : and thirteen cases of ectopic gestation among 1,704 cases of pregnancy, or once in eacl 131 pregnancies!

Considering the pathologic diagnoses which have been made in the laboratory, it is seen that 86 , or 5.33 per cent. of the pregnant patients were sent into the hospital because of bleeding, and were curetted. A study of these curettements has shown that thirteen of the 86 patients, or nearly 17 per cent. of possible abortions, were flowing because they were suffering with a misplaced pregnancy.

This does not indicate the relative frequency of abortion to pregnancy, which has been estimated by Taussig as high as one abortion to every 2.3 labors, but will, I believe, call attention to the possibility of

\footnotetext{
5. Tanssig: Preventicn and Treatment of Abortion, St. Ionis, 1910.
} 
confusing ectopic gestation with incomplete abortion and should put the general practitioner on his guard when treating such cases.

Albucasis, ${ }^{\circ}$ an Arabian surgeon of the eleventh century, is said to have first described ectopic pregnancy. For generations the etiology of the condition was little understood, but gradually the idea prevailed that, in many cases at least, an inflammatory condition of the adnexa was the predisposing cause.

Dr. William Campbell ${ }^{7}$ accumulated these data and published a monograph which later formed the basis of Parry's ${ }^{8}$ work and to whom Lawson Tait ${ }^{9}$ gives great credit in discussing the subject.

Lawson Tait" said, "I believe it to be more than likely that the real cause of this accident is the coincidence of a set of circumstances the most important of which is the destruction or insufficiency of the ciliary movement." Since Tait made this statement, however, investigators have shown that of ten the cilia are not destroyed. Moreover, the condition of round-cell infitration, of destruction of the surface epithelium, of agglutination of the septa of the tubes, of edema and fibrosis, which are frequently present in the ectopic tube, are stated by some pathologists to depend on the condition of the existing pregnancy or the recent rupture of the tube rather than a preexisting inflammation. Careful sections of the tubes also show that in some cases the ovum has lodged in a blind passage supposed to be a congenital abnormality.

Webster ${ }^{\circ}$ states that the ovum always imbeds in mïllerian tissue and Huffman, ${ }^{11}$ on theoretic considerations, carries his idea farther by stating that the ovum always imbeds, in cases of ectopic pregnancy, in anomalous imbedding areas. While these theories are attractive, they lead away from the clinical idea of inflammation and tend to place the predisposing cause of the condition on an unchangeable hereditary basis rather than on the basis of previous inflammatory affections which are preventable. Moreover, it should not be forgotten that decidual reaction of early pregnancy has been noted in the tissues of practically all the organs of the lower abdomen, including the omentum and the appendix. ${ }^{12}$ Leo Loeb $^{13}$ recently concludes that guinea-pigs do not have ectopic pregnancy because it is impossible to create in them a deciduai reaction outside the uterus. One reason for the frequency of ectopic gestation in human beings undoubtedly depends on the ability of the tissues into which the ovum penetrates to develop decidua, which affords the ovum an adequate soil for development, but this does not eliminate the fact that pelvic inflammations often result in deformities of the tubes, which causes the ovum not infrequently to imbed outside the uterus.

A clinical summary of the cases here reported is presented in chart form and from this it will be seen that the average age, the multigravida, the number of preceding induced and spontaneous abortions as well as attacks of gonorrhea, the period of relative sterility and the microscopic findings all point strongly

\footnotetext{
6. Aboulcassem Khalaf ben Abbas Ezzahraony.

7. Campell, William: A Memoir on Extra Uterine Gestation, Edinburgh, 1842 .

8. Parry: Extra Uterine Pregnancy: Its Causes, Species, Pathologica Anatomy, Clinical History, Diagnosis, Prognosis and Treatment, Philadelphia, H. C. Lea, 1876 .

9. Tait, R. Lawson: Diseases of Women, Philadelphia, Lea, 1879.

10. Webster: Study of a Specimen of Ovarian Pregnancy, Am. Jour. Obst., 1904, L, 28.

11. Huffman, Otto V.: A Theory of the Cause of Ectopic Pregnancy, The Journal A. M. A., Dec. 13, 1913, p. 2130.

12. Meyer, R.: Ektopiche Decidua, Ztschr. f. Geburtsh. u. Gynäk $1914,1 \times x y, 760$.

13. Loeb, Leo.: Tr. Soc. Exper. Biol, and Med., 1913, xi.
}

to the clinical idea of Tait that many of the cases of ectopic gestation trace their etiology to a preceding pelvic infection. It might be added that gonorrhea plays the minor role, and that abortion, associated as it so often is with a more or less noticeable attack of salpingitis, is the major predisposing cause for this frequent, dangerous anomaly of pregnancy.

\section{CONCLUSIONS}

From a statistical study of 36,668 clinic patients, the relative frequency of ectopic pregnancy is estimated as follows:

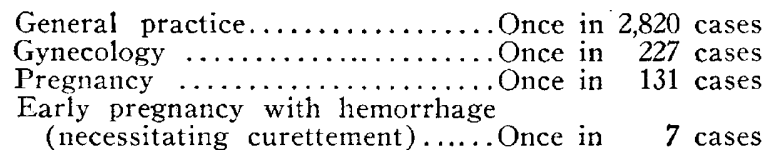

(necessitating curettement)...... Once in

Lane Hospital.

\section{ABSTRACT OF DISCUSSION}

Dr. Joseph B. De Lee, Chicago: Ectopic gestation occurs not infrequently in the lower animals, the horse especially, the cow and others. I know an interesting case in a house dog, running for six or eight weeks with symptoms of peritonitis. A roentgenogram disclosed the location of the fetus, an operation was performed, and a happy recovery made. As to the frequency of ectopic gestation, in my eariy years, in my hospital services everything except the actual delivery of a baby was assigned to the surgeon or to the gynecologist, and therefore, the obstetrician did not get the cases. He was considered perhaps one or two degrees better than a midwife, and of a different sex. This was the only distinction that I could learn. But as I began to assert my rights, and obtained all the obstetric cases, I found that the frequency of extrauterine pregnancy was increased. Perhaps we are losing sight of the point that so-called colics shortly after marriage, sometimes diagnosed as appendicitis, are not infrequently ectopic gestation aborting through the tube. You all know prostitutes' or actress' colic, and occasionally you hear of an actress being carried off the stage in a fainting condition. These are frequently cases aborting through the fallopian tube, and if properly diagnosed would increase the number of ectopic gestations which occur.

Dr. Alfred B. Spalding, San Francisco: I am not ve:y much of a veterinarian and cannot dispute the point with Dr. DeLee about the ectopics occurring in the lower animals, but a great deal of work along this line has been done by others and many of the supposed cases of the ectopics in lower animals have been considered to be due to rupture of the uterus and to a secondary implantation of the ovum in the abdominal cavity.

Also the relation of the tube to the double uterus in the lower animals is different from that found in the human being. Loel's work was on guinea-pigs. He found that it was impossible to make them have an ectopic pregnancy by any mechanical or experimental means, and they are not supposed to have an ectopic from natural causes. He was able in one case to get a supposed ectopic from a suspected rupture in the tube, which later was found to be a rupture of that part of the uterus which forms the connecting link between the two.

Responsibility in Rural Sanitary Improvement.-Again, this is within the purview of the county health officer. But the broadening of the outlook of the resident of the rural district is not the obligation of one man or one profession. The duty is shared by the church, the sociologist, the teacher, the minister, the welfare worker, in fact by all who bear responsibility because of position or knowledge. Where to begin is a point to be considered by each institution or worker in his own locality, but that each should do his part admits of no discussion.-Oscar Dowling, American Journal of Public Health, May, 1915. 